University of Nebraska - Lincoln

DigitalCommons@University of Nebraska - Lincoln

Investigations of the Ichthyofauna of

Nicaraguan Lakes

Papers in the Biological Sciences

1976

\title{
Competition between Color Morphs of the Polychromatic Midas Cichlid Cichlasoma citrinellum
}

George W. Barlow

University of California - Berkeley

Follow this and additional works at: https://digitalcommons.unl.edu/ichthynicar

Part of the Aquaculture and Fisheries Commons

Barlow, George W., "Competition between Color Morphs of the Polychromatic Midas Cichlid Cichlasoma citrinellum" (1976). Investigations of the Ichthyofauna of Nicaraguan Lakes. 33.

https://digitalcommons.unl.edu/ichthynicar/33

This Article is brought to you for free and open access by the Papers in the Biological Sciences at DigitalCommons@University of Nebraska - Lincoln. It has been accepted for inclusion in Investigations of the Ichthyofauna of Nicaraguan Lakes by an authorized administrator of DigitalCommons@University of Nebraska Lincoln. 


\section{Competition between Color Morphs of the Polychromatic Midas Cichlid Cichlasoma citrinellum}

Abstract. The Midas cichlid, Cichlasoma citrinellum, is a polychromatic fish that occurs in Nicaragua. All of these fish start life as normally colored, cryptic individuals. In some populations a few fish change into conspicuously colored morphs, most frequently gold. When kept in unmixed color groups, golds and normals grow at the same rate; but when they are mixed, growth of the golds becomes faster and that of the normals slower. Golds dominate normals in contests over food, which accounts for their advantage.

A large literature has accumulated on polychromatism (color polymorphism) in many different groups of animals, such as clams, snails, insects, birds, and fishes (1). The adaptive significance of polychromatism, in cases other than sexual dimorphism, has often been disputed but seldom documented. Where conspicuous morphs exist, many have argued that the explanation lies in differential predation. The advantages and disadvantages of being of a particular color are said to depend on the relative and absolute frequencies of the various morphs, as well as on the colors of the environment in which they occur (2). In some species, polychromatism is thought to occur as a form of mimicry; in others, it may be related to climatic factors (3).

More relevant here are situations in which differential coloration is of significance in competitive social interactions. Examples are rare. One, however, is the competition for access to females that occurs among male ruffs at their breeding leks. The central male birds, who enjoy the greatest access to females, have dark-colored necks. Peripheral males with white necks are also able to inseminate some females; Hogan-Warburg (4) hypothesized that the white neck color inhibits attack by the dark-necked males.

Species of herons and egrets commonly occur in two color phases, blue and white. The differently colored morphs tend to feed in different parts of their environment-the white forms more out in the open than the blue, especially when it is the only species present (5). Such habitat partitioning should reduce competition for food within the species.

The Midas cichlid Cichlasoma citrinellum Günther is one of the most abundant cichlid fishes in the lakes of Nicaragua. Most individuals display the characteristic color pattern of cryptically marked fishes: a grayish background with changeable, species-typical black markings and some color highlights. I call this color pattern "normal." The more colorful morphs start life as normals, but they lose their speciestypical markings at various ages and become white, yellow, orange, or even reddish. Some individuals have dark brown or black blotches, and some are mixtures of the various colors. The yellow through orange morphs are the most common and, for convenience, are termed "gold." Golds cannot change their markings after they have metamorphosed, although their colors intensify when they breed. (In some lake populations, up to 8 to 10 percent of the adults are conspicuous morphs, while in others all fish are normal.)

All four possible combinations of sex and color have bred successfully in the laboratory. Young golds in any group of siblings ultimately became the largest, even though the change in color was not a function of the relative or absolute size of the fish. Work then in progress (6) showed that, all else being equal, golds dominate normals. I hypothesized that the differential growth rates were the result of the golds

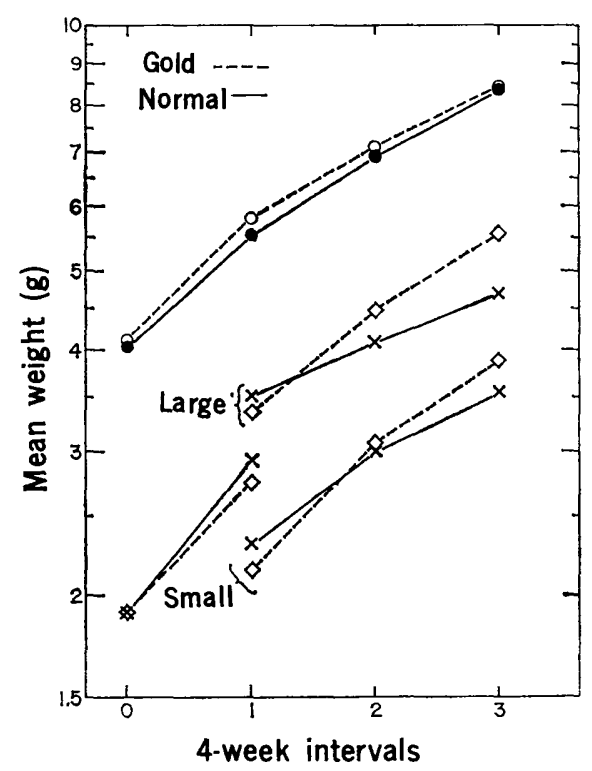

Fig. 1. The increase in mean weight of open squares, golds; closed circles and $x$ 's, normals. groups of Midas cichlids at successive intervals of 4 weeks each. Open circles and possessing a competitive advantage in conflicts over food, due to the dominance effect. If so, golds should grow faster than normals when in mixed groups; but when kept in groups where all fish are the same color, golds and normals should grow at the same rate.

Young fish were sorted into four groups. A gold group and a normal group of 16 large fish each were selected so that the fish in the two groups were closely matched in weight. In parallel, a gold group and a normal group of 16 small fish each were also selected and matched for weight (Fig. 1 ; starting groups, time interval 0 ). Since each starting group consisted of but one color, all served as controls. Each group of fish was placed randomly into one of four adjacent but visually separated aquariums in a heated aquarium room (7).

The fish were fed twice daily, usually on Clark's trout chow $(1.31 \mathrm{~g}$ of dry food per $100 \mathrm{~g}$ of fish per meal). This staple was supplemented by occasional meals of live adult brine shrimp, Artemia salina $(8.30 \mathrm{~g}$ of wet shrimp per $100 \mathrm{~g}$ of fish). Most of the food was eaten quickly, but a small amount always remained after the initial burst of feeding.

Four weeks after beginning the experiment, the fish were weighed again. I returned the unmixed groups of large golds and large normals to different aquariums (assigned by lot) to serve as continuing controls. Now the critical test of the hypothesis started. The two groups of small individuals were divided into the eight largest and eight smallest fish-the eight largest golds and eight largest normals being put together in one tank. Into another tank were placed the eight smallest fish from each group of small golds and normals. Thus there were now two experimental groups, one of larger and one of smaller fish, each consisting half of golds and half of normals of almost the same size (Fig. 1 ; groups at 4 -week interval 1). These groups were then left intact for the remainder of the experiment. All fish were weighed and compared two more times: 4 and then 8 weeks after the experimental recombination (Fig. 1; intervals 2 and 3 , respectively).

All control groups grew at the same rate. When golds and normals were maintained separately but under the same conditions, there were no significant differences in their growth.

In contrast, in the experimental groups that had fish of mixed colors, golds grew faster than normals. Ini- 
tially (interval 1) the mean weight of golds in both groups was slightly smaller than that of the normals, although the differences were not significant. After 4 weeks, the golds in the group of larger fish had attained and exceeded the mean weight of the normals, but the difference only approached significance $(P=.12)$. However, when the individual weight gains were compared (difference in weight for each fish between the start and the end of the 4-week interval) the golds had grown faster than the normals $(P<$ $.001)$.

In the same comparison for the group of smaller experimental fish, golds caught up with normals after 4 weeks, and their mean weight was not significantly different $(P=.48)$. Again, the gains in weight were greater in golds than in the normals $(P=.032)$.

After an additional 4 weeks, the differences within the experimental groups were yet larger. The mean weight of the golds in the group of larger fish was now significantly greater than that of the normals $(P=.027)$, and the gain in weights of the individuals was again significantly higher for the golds $(P=.014)$. In the group of smaller fish, the difference in mean weight between golds and normals increased further in the golds' favor, but the difference was still not significant $(P=.36)$. The gain in weights of the individuals, however, was again significantly greater among the golds $(P=.032)$.

The experiment confirmed the general observation that, when Midas cichlids are kept in groups having both normals and golds, the golds grow faster than the normals. The behavioral mechanism responsible for this difference is the advantage golds have in aggressive behavior over that of normals (6). This aggressive behavior is translated into improved access to food (8), particularly right after the initial rush to obtain food (9).

One curious result of this experiment was that the controls were in such remarkable agreement. Fighting involves the expenditure of energy and potentially results in injury and disturbance of the endocrine physiology (10). If gold and normal fish differ in aggressiveness, then the more aggressive golds would be expected to fight more among themselves, and consequently their growth should be slower (11). This problem will be treated elsewhere ( 8 , 9).

This work on the Midas cichlid suggests that colorful gold morphs have an advantage over the normal, cryptically colored individuals in direct intraspecific competition for food. The advantage, however, disappears when all the fish are of the same color. Since there must be counterselective forces, perhaps predation, working against the brilliantly colored morphs, one would anticipate the continuance of polychromatism at a level appropriate to the ecological setting of each population. If the competition were interspecific, with a closely related species, one could predict the evolution of one species in which all individuals are brightly colored.

George W. Barlow Department of Zoology and Museum of Vertebrate Zoology, University of California, Berkeley 94720

\section{References and Notes}

1. G. Fryer, Proc. Zool. Soc. London 132, 153 (1959); W. Hovanitz, Symp. Soc. Exp. Biol. 7, 238 (1953); J. Huxley, Acta Congr. Int.

Ornithol. 11, 309 (1955); C. Kosswig, Copeia 1964, 65 (1964); G. B. Moment, Science 136, 262 (1962).

2. J. A. Allen, Nature 237, 348 (1972); B. Clarke, Bull. Syst. Assoc. 4, 47 (1962); H. B. D. Kettlewell, Heredity 10, 287 (1956)

3. C. H. F. Rowell, Advan. Insect Physiol. 8, 145 (1971); R. K. Selander, Avian Biol. 1, 57 (1971).

4. A. J. Hogan-Warburg, Ardea 54, 8 (1966)

. R. K. Murton, Ibis 113, 97 (1971).

6. G. W. Barlow and P. Ballin, in preparation.

7. The aquariums were 60 by $60 \mathrm{~cm}$ and $28 \mathrm{~cm}$ deep (101 liters); temperature $26^{\circ}$ to $28^{\circ} \mathrm{C}$. water continuously aerated and filtered, and changed weekly; 13-hour photoperiod.

8. G. W. Barlow, D. H. Bauer, K. R. McKaye, in preparation.

9. G. W. Barlow and K. R. McKaye, in prepa-

10. B. E. Eleftheriou and J. P. Scott, Eds. The Physiology of Aggression and Defeat (Plenum, New York, 1971).

11. One could assume that golds have a faster intrinsic rate of growth than normals, but that this advantage is canceled by the effect of fighting. However, other work (G. W Barlow and $S$. J. Wallach, in preparation) has shown that groups of golds and of normals are about equally aggressive after they have been together for a few days.

12. I am grateful to $L$. Machlis and $R, F$, Green for their help, and to A Bond and C. J. for their help, and to $A$. Bond and C. J. Berg for commenting on the manuscript. S2192X.

30 August 1972; revised 20 October 1972 